(c) American Dairy Science Association, 2007.

\title{
Altered Vocalization Rate During the Estrous Cycle in Dairy Cattle
}

\author{
P. C. Schön, ${ }^{1}$ K. Hämel, B. Puppe, A. Tuchscherer, W. Kanitz, and G. Manteuffel \\ Forschungsinstitut für die Biologie landwirtschaftlicher Nutztiere, Dummerstorf, D-18196, Germany
}

\begin{abstract}
Correct detection of estrus is a problem in dairy herds. In practice, several procedures exist for detection of estrus besides conventional visual observation by humans. These procedures deliver very different results regarding detection of estrus. It is known that the calls of female mammals can contain information about reproductive status. It is also suspected that the vocalizations of cattle contain information about age, sex, dominance status, and stage in the estrous cycle. In the present study, a methodology for the continuous automatic recording of vocalization of heifers during the periestrous period is presented. It was shown in 10 tethered heifers that the estrous climax results in an increase in vocalization rate. Vocalization rate of heifers increased approximately $84 \%$ from d -2 to 0 (related to observed estrus) and approximately $59 \%$ from $\mathrm{d}-1$ to $d 0$. After $d 0$, vocalization rate decreased about $79 \%$. Increased vocalization was correlated with the visual observation of estrus by humans. We also found 2 different structures in the vocalization of heifers. The harmonic structure showed regular frequency bands, whereas the nonharmonic structure was noisy. The hypothesis that the disharmonic structure increases near the estrous climax was confirmed. Hence, it seems possible to get information about stage of the estrous cycle of dairy cattle by means of monitoring vocalization. The presented method of automatically detecting the rate of cattle vocalization (patent pending) could be used solely or in combination with other automated systems for detecting estrus and could considerably increase current estrus detection rates once its applicability can be demonstrated in nontethered cattle.
\end{abstract}

Key words: estrus detection, vocalization, dairy cattle

\section{INTRODUCTION}

Detection of estrus in dairy cattle, and in this context, the choice of the most favorable insemination time, is an important management factor in the dairy industry.

Received April 7, 2006.

Accepted August 23, 2006.

${ }^{1}$ Corresponding author: schoen@fbn-dummerstorf.de
In practice, several procedures exist to facilitate detection of estrus besides conventional visual observation by humans (Saumande, 2002; Peralta et al., 2005; Roelofs et al., 2005). Methods for detection of estrus produce different estrus detection rates (Becker et al., 2005), ranging from 60 to $80 \%$ in dairy herds (Esslemont, 1992; Ferguson and Galligan, 1993; Hospes et al., 2005). In practice, estrus detection rates are usually $<60 \%$. Becker et al. (2005) stated that visual observation by responsible persons delivers the best estrus detection rates. Taking into account large herds of high-producing milk cows, a need for reliable and affordable automated methods of detecting estrus is clear.

In some mammals, evidence exists that calls of females can contain information on the reproductive status. Semple and McComb (2000) found in replay experiments that male Barbary macaques were able to differentiate among stages of the estrous cycle of females by mating calls. In elephants, increased vocalization rate during the mating season was observed (Leong et al., 2003). Few papers on vocalization in cattle exist. Some authors tried to describe qualitatively (Liebenberg et al., 1977; Hall et al., 1988; Laube et al., 1988) or classify methodically (Kiley, 1972; Jahns et al., 1997; Ikeda and Ishii, 2001) different forms of vocalization. Kiley (1972) identified 6 different calls, but they occurred as a part of a continuum and less as discrete events. Furthermore, communicative functions of vocalizations in cattle were investigated; for example, mutual recognition of mothers and calves (Barfield et al., 1994; Marchant-Forde et al., 2002). It also was suggested that vocal behavior of cattle might be used as an indicator of their physiological and mental condition (Watts and Stookey, 2000; Manteuffel et al., 2004). Watts and Stookey (2000) suspected that the vocalization of cattle contained information about age, sex, dominance status, and stage of the estrous cycle.

No evidence of a connection between vocalization and estrous cycle in dairy cattle is found in the literature. Therefore, we investigated vocalization during the periestrous period in parallel with concentrations of blood progesterone and visual observation for sexual behavior. The paper presents the course of vocalization rate and structure of calls of periestrous heifers. If a measurable change in vocalization traits could be shown, development of a procedure based on vocalization changes 
would make possible a practical, automated method for detecting estrus on the farm. It could lead to better estrus detection rates alone or in combination with other procedures.

\section{MATERIALS AND METHODS}

\section{Housing and Observation for Estrus}

Ten German Holstein heifers (18 to 22 mo of age) were used in the experiment. The heifers were kept tethered in one stable under the same conditions. For vocalization recordings, the heifer to be examined was separated approximately $15 \mathrm{~m}$ from the next closest heifer. Otherwise, the heifer remained in her normal surroundings within view and vocal contact of other heifers. By maintaining the separation distance from the next heifer, recording of calls of other heifers was avoided. The separated heifer was kept under the same conditions as other heifers. Heifers were fed a TMR twice daily. The experiment was conducted between February and July 2004.

Generally, the estrous cycle lasts 18 to $23 \mathrm{~d}$ in cattle and can be 2 to $3 \mathrm{~d}$ shorter in heifers. In all experimental heifers, estrus was documented beginning in March 2003. Visual observation of estrus was carried out daily at 0800 and $1500 \mathrm{~h}$. Sexual behavior, redness and swelling of the vulva, and the secretion of mucus were classified by experienced herd personnel as weak, average, or strong.

\section{Determination of Progesterone Concentration and Induction of Estrus}

To determine concentrations of progesterone, blood (5 to $6 \mathrm{~mL}$ ) was collected from a tail vessel beginning $11 \mathrm{~d}$ after the last observed estrus ( $\mathrm{d} 0=$ estrus) for 5 $\mathrm{d}$ at $0800 \mathrm{~h}$. Concentration of progesterone in blood plasma was determined by using a direct, competitive tritium RIA. The assay tracer used [1, 2, 6, 7- $\left.{ }^{3} \mathrm{H}\right]$-progesterone (Amersham Pharmacia Biotech, Freiburg, Germany). An antibody was produced by immunization of rabbits against an 11-OH-progesterone conjugate. Separation of the bound antibody from the free steroid was carried out by adding Dextran-coated charcoal. Intra- and interassay coefficients of variation were 8.0 and $9.6 \%$, respectively (Schneider et al., 2002).

Estrus was induced by injecting $0.5 \mathrm{mg}$ of $\mathrm{PGF}_{2 \alpha}$ i.m. (Cloprostenol; Veyx Pharma, Schwarzenborn, Germany). Interval to estrus was 2 to $3 \mathrm{~d}$ after injection. When estrus was synchronized, $\mathrm{PGF}_{2 \alpha}$ was administered on $\mathrm{d} 12(0800 \mathrm{~h})$ of the cycle. Visual observation of estrus was carried out daily at 0800 and $1500 \mathrm{~h}$. Vocalization recordings began on $\mathrm{d} 11$ at $0800 \mathrm{~h}$ and ended on d 16 at $0800 \mathrm{~h}$. Calls were recorded and analyzed continuously throughout that period.

\section{Vocalization Recordings and Evaluations}

Vocalizations were recorded with a radio microphone system (Evolution Wireless Series EW 112 G2, Sennheiser, Wedemark/Hannover, Germany) from $0800 \mathrm{~h}$ on d 11 until $0800 \mathrm{~h}$ on $\mathrm{d} 16$. The wireless recording system consisted of a clip-on microphone (ME 2, condenser, ball, Sennheiser), a transmitter (SK 100 G2, Sennheiser), and a stationary receiver (EM 112 G2, Sennheiser). The microphone was attached at a neck harness in direct proximity to the head of the heifer. The receiver was connected to the sound card of the computer. Digitization was carried out with a sampling rate of $22,050 \mathrm{~Hz}, 16$ bits accuracy, and mono sound quality. The aim of the vocalization recordings was to separate recordings of single calls together with the corresponding time and date. A recording algorithm using the graphic programming surface language LabVIEW (LabVIEW, 1999) was developed, which generated serial signal windows of $250 \mathrm{~ms}$ from the recording. These signal windows were shorter than a complete single vocalization. Subsequently, the mean of the signal windows was determined. To restrict recordings to significant events only, signal windows with means exceeding a selected threshold were considered. The threshold was chosen so that only sound events from a short distance were recorded. We defined a signal as a series of adjacent signal windows in which the first window exceeded the threshold and the subsequent windows remained above the threshold (holding). To get the signal with the correct beginning and end, the window ahead of the first above-threshold signal window started the series of signal windows and the first below-threshold window ended it. Calls were, therefore, separated by times of zero-signal windows, which were not evaluated. The series of nonzero signal windows were lined up, labeled temporally, and stored as single calls. Occasionally, noise signals occurring on the sound recordings (mainly from management operations) were eliminated manually using a special LabVIEW program. Subsequently, the number of calls per hour was determined. Daily vocalization rate was determined by summing up the number of vocalizations per heifer in a 24 -h period ( 0800 to $0800 \mathrm{~h}$ on the following day).

Two different structures in the calls of the heifers were revealed. The first was a harmonic sound, which was termed the "moo" call or call section. The second structure was noisy and was termed the "bellow" call or call section. Figure 1 shows the sonogram of a typical call recording of a heifer. In this diagram, the frequency structure over time is represented. Clearly, 3 sections 


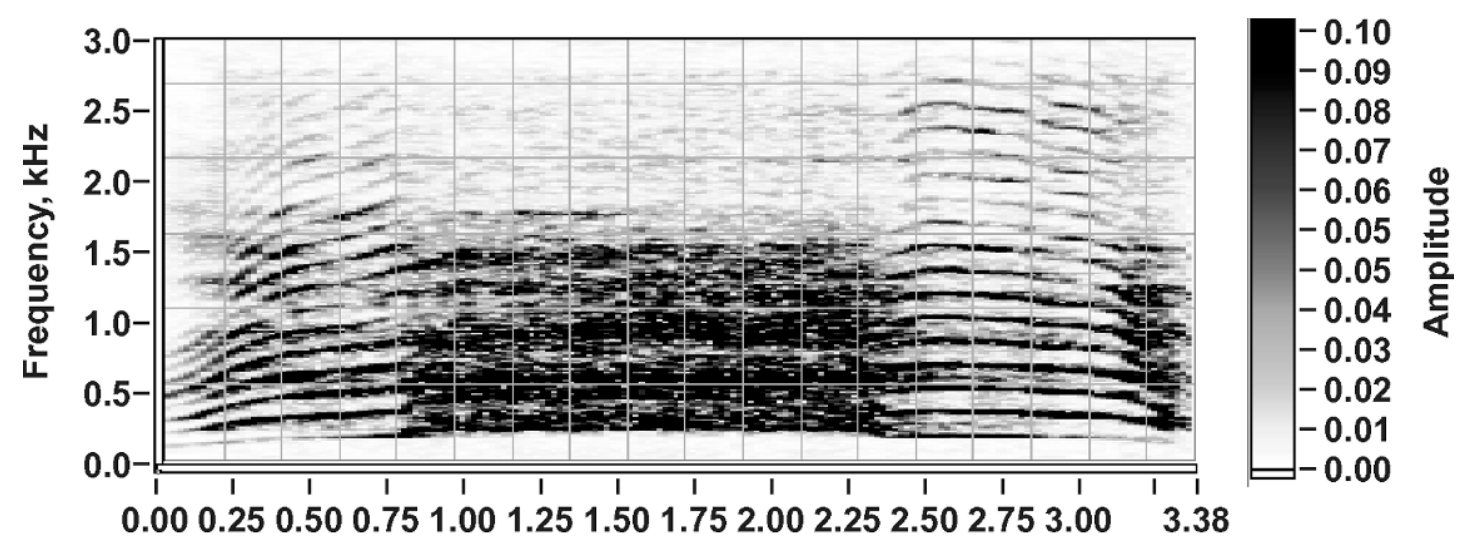

Time, $\mathbf{s}$

Figure 1. A heifer call consisting of 3 parts: a beginning harmonic, a middle nonharmonic, and an ending harmonic part.

are recognizable: a beginning section with frequency bands, a middle unstructured section, and another structured section with frequency bands at the end. The envelope of the cepstrum (additional Fourier transformation of the frequency spectrum) has proven to be well suited for the modeling of such calls (Schön et al., 1999). Hence, envelopes of the cepstrums were used for automatic classification of the time windows into harmonic and nonharmonic parts. As the result, the single time windows (call sections) were classified as harmonic moo or nonharmonic bellow. If more than half of the time windows in a call were harmonic, the whole call was classified as a harmonic moo call, and otherwise as a nonharmonic bellow call. For the complete vocalization (vocalization rate), the rate of the moo and bellow calls was determined.

\section{Statistical Analyses}

The course of the vocalization rate, moo calls, and bellow calls as well as the course of progesterone concentration were synchronized to the day of observed estrus (d 0). Statistical analysis was carried out by using SAS System for Windows (SAS Institute, 2001). Elementary statistics and frequency tables were calculated by using PROC MEANS and PROC FREQ (SAS Institute, 2001). The frequency data (response variables: proportions of bellow calls/total calls and moo calls/total calls) were analyzed by using the GENMOD procedure consisting of a logistic model including day of cycle for these binary data and taking into account the repeated measures of each heifer on the days of cycle. Count data (number of total calls, bellow calls, and moo calls) were analyzed by using the GENMOD procedure, but on the basis of a Poisson regression in a log-linear model including day of cycle, and taking into account repeated measures of each heifer.

Continuous data (progesterone concentrations) were analyzed by using 1-way ANOVA in the MIXED procedure including day of cycle and taking into account repeated measures of each heifer. In addition, least squares means and their standard errors (SE) were calculated and tested pairwise (frequency and count data: $\chi^{2}$ test; continuous variables: multiple $t$-test). Spearman correlation coefficients between progesterone concentration and vocalization were estimated and tested vs. the null with the CORR procedure (SAS Institute, 2001).

\section{RESULTS}

All heifers vocalized during the examination period. The number of vocalizations differed considerably between heifers and ranged between 36 and 835 vocalizations per heifer during the complete recording time. Mean vocalizations/h for all heifers are depicted in Figure 2. In 8 heifers, estrus was confirmed $2 \mathrm{~d}$ after $\mathrm{PGF}_{2 \alpha}$ injection, in 1 heifer $1 \mathrm{~d}$ after injection, and in 1 heifer $3 \mathrm{~d}$ after injection. Increase in the vocalization rate around the time of the visually detected estrus can be seen in Figure 2.

Table 1 shows daily vocalization rate, numbers of moo and bellow calls, progesterone concentration, and the parts of moo and bellow calls of the whole vocalization rate synchronized to $\mathrm{d} 0$. For all investigated traits, an influence of the day of cycle was revealed $(P<0.05)$. We found a strong increase in vocalization rate $1 \mathrm{~d}$ before estrus was detected. On $d 0$, the rate increased again from 70 to 171 calls. Hence, the vocalization rate of heifers increased approximately $84 \%$ from $d-2$ to 0 , 


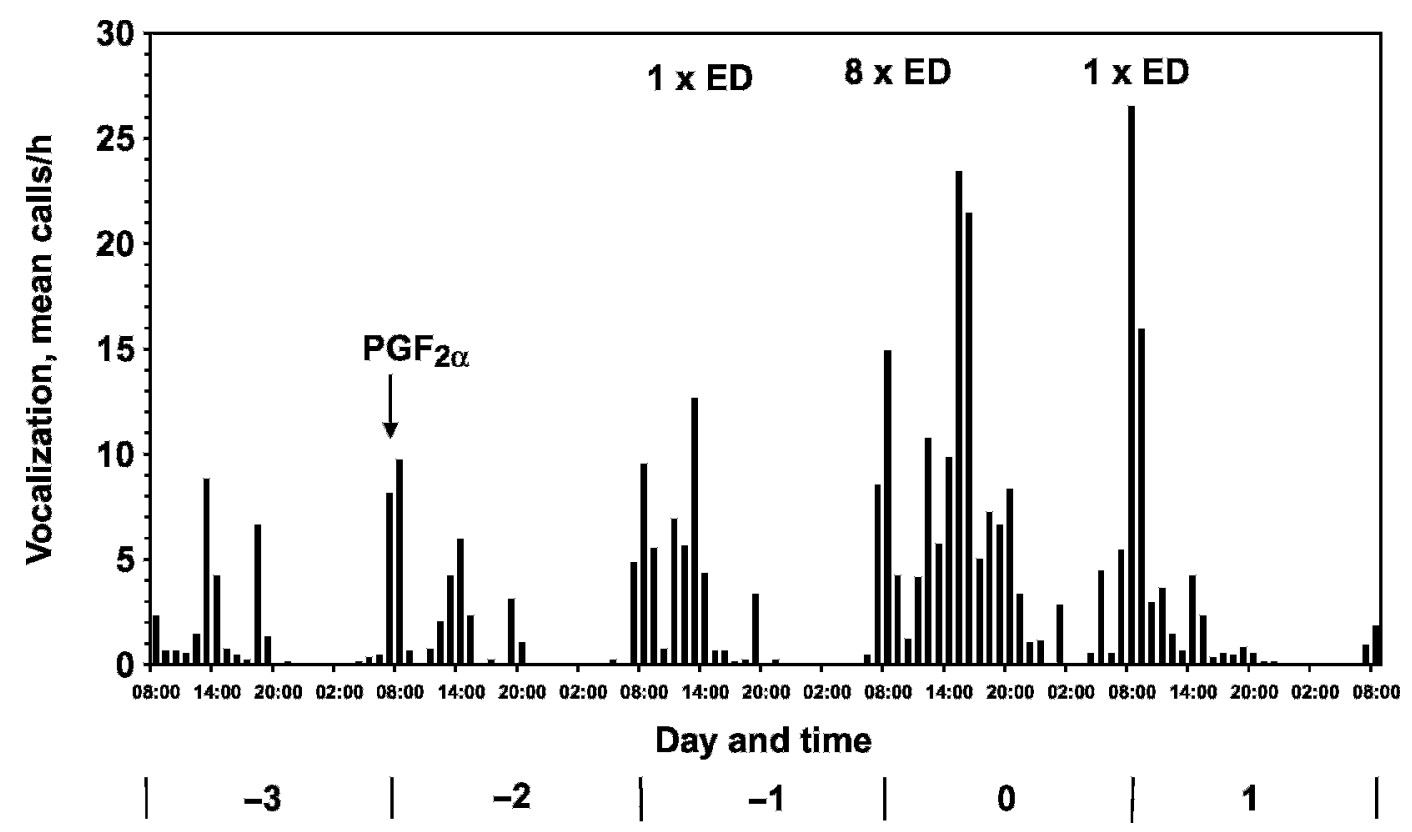

Figure 2. Mean number of calls per hour (bars) and visual estrus detection (ED) during the recording time for all heifers.

and approximately $59 \%$ from $d-1$ to 0 . After $d 0$, the vocalization rate of heifers decreased about $79 \%$. Large standard errors show, however, that the reaction of individual heifers was very different. The same tendency was detected for moo and bellow calls, but the number of the bellow calls increased more than number of moo calls from $d-2$. This effect is even more pronounced when examining the parts of the moo or bellow vocalizations in the whole vocalization. We found an increase in parts of bellow calls on $d-2$ and a decrease from d 0 to 1 .

Concentrations of progesterone were also influenced $(P<0.001)$ by day of the estrous cycle. Comparison in pairs yielded differences between the $d-3,-2,-1$ (before estrus), d 0 , and 1 (during and after estrus) values. We found no correlation between progesterone and vocalization rate $(\mathrm{r}=-0.189 ; P=0.214)$. The 2 traits seem to be inversely related on $\mathrm{d} 0$, because concentrations of progesterone were elevated before $d 0$ and reduced on $\mathrm{d} 0$ and 1 , whereas vocalization rate peaked on $\mathrm{d} 0$, and then decreased thereafter.

\section{DISCUSSION}

To optimize productivity of dairy cattle, detection of (often very short) periods of estrus is essential. The aim of the present study was to develop a method for the continuous automated recording of cattle vocalizations

Table 1. Vocalization rate, bellow and moo calls, proportions of bellow and moo calls, and progesterone concentration levels during the estrous cycle

\begin{tabular}{|c|c|c|c|c|c|c|c|c|c|c|c|c|}
\hline \multirow[b]{3}{*}{ Day of cycle ${ }^{1}$} & \multicolumn{6}{|c|}{ Absolute vocalizations, ${ }^{2}$ no. } & \multirow{2}{*}{\multicolumn{2}{|c|}{$\begin{array}{c}\text { Progesterone, }{ }^{3} \\
\text { ng/mL }\end{array}$}} & \multicolumn{4}{|c|}{ Vocalizations, ${ }^{4} \%$} \\
\hline & \multicolumn{2}{|c|}{ Total } & \multicolumn{2}{|c|}{ Moo calls } & \multicolumn{2}{|c|}{ Bellow calls } & & & \multicolumn{2}{|c|}{ Moo calls } & \multicolumn{2}{|c|}{ Bellow calls } \\
\hline & Mean & SE & Mean & SE & Mean & SE & Mean & $\mathrm{SE}$ & Mean & SE & Mean & SE \\
\hline-3 & $32.3^{\text {ace }}$ & 13.1 & $23.2^{\text {ace }}$ & 10.5 & $9.1^{\text {ace }}$ & 4.8 & $3.2^{\mathrm{a}}$ & 0.1 & $71.8^{\mathrm{a}}$ & 11.1 & $28.2^{\mathrm{a}}$ & 11.1 \\
\hline-2 & $28.0^{\text {ace }}$ & 14.6 & $14.7^{\text {ace }}$ & 7.1 & $13.3^{\text {ace }}$ & 8.5 & $3.1^{\mathrm{a}}$ & 0.1 & $52.5^{\mathrm{bc}}$ & 10.3 & $47.5^{\mathrm{bc}}$ & 10.3 \\
\hline-1 & $70.2^{\text {ade }}$ & 19.4 & $35.9^{\text {ade }}$ & 9.0 & $34.3^{\text {bde }}$ & 12.2 & $3.1^{\mathrm{a}}$ & 0.1 & $51.1^{\text {bd }}$ & 6.7 & $48.9^{\text {bd }}$ & 6.7 \\
\hline 0 & $171.2^{\mathrm{bdf}}$ & 61.5 & $77.1^{\text {bdf }}$ & 25.2 & $94.1^{\mathrm{bdf}}$ & 39.7 & $0.7^{\mathrm{b}}$ & 0.1 & $45.0^{\mathrm{b}}$ & 6.5 & $55.0^{\mathrm{b}}$ & 6.5 \\
\hline 1 & $35.3^{\text {ace }}$ & 11.4 & $21.4^{\text {ace }}$ & 5.4 & $13.9^{\text {ace }}$ & 6.3 & $0.6^{\mathrm{b}}$ & 0.1 & $60.7^{\text {acd }}$ & 6.0 & $39.3^{\text {acd }}$ & 6.0 \\
\hline
\end{tabular}

a-fValues within column having different superscript letters differ $(P<0.05)$.

${ }^{1}$ Day of the estrous cycle ( 0 = estrus) was synchronized after injection of prostaglandin $\mathrm{F}_{2 \alpha}$.

${ }^{2}$ The calls were recorded and analyzed continuously over the entire period ( $d-3$ to 1 ).

${ }^{3}$ Concentrations of progesterone were determined in blood samples collected daily at $0800 \mathrm{~h}$.

${ }^{4}$ Proportion of total vocalization that was either moo or bellow calls. 
during the estrous cycle. In a pilot experiment in tethered heifers, sound recordings showed increased vocalization rate and an elevated proportion of bellow calls during estrus in all examined heifers. Increase in vocalization rate coincided with the estrus as observed visually by herd personnel. The method described here has been registered for a patent (Schön et al., 2005).

Further investigations are necessary to monitor the course of vocalization rate and progesterone concentrations during a longer period around estrus and for multiple cycles across individuals. Continued work with regard to practice will examine solutions for applying this methodology in free-stall housing. Possible influences of age (number of lactations) and milk yield of cows must also be considered. One of the main problems might be the large individual variability of absolute calling rate, because we found only a relative increase of vocalization compared with the individual vocalization rate before estrus. To detect this trait in a technically and practically affordable way will be a challenging task. Furthermore, as long as the results are based on vocalization of only tethered heifers, it must be determined whether the calls are caused by social stress (e.g., lacking of physical contact to herdmates) or whether calls are really an expression associated with estrus (e.g., biologically aimed to attract the bull).

\section{ACKNOWLEDGMENTS}

The authors thank the 3 anonymous reviewers and the editor for helping to improve the manuscript.

\section{REFERENCES}

Barfield, C. H., Z. Tang-Martinez, and J. M. Trainer. 1994. Domestic calves (Bos taurus) recognize their own mothers by auditory cues. Ethology 97:257-264.

Becker, F., W. Kanitz, and W. Heuwieser. 2005. Vor- und Nachteile einzelner Methoden der Brunsterkennung beim Rind. Züchtungskunde 77:140-150.

Esslemont, R. J. 1992. Measuring dairy herd fertility. Vet. Rec. 131:209-212.

Ferguson, J. D., and P. T. Galligan. 1993. Prostaglandin synchronization programs in dairy herds. Compend. Contin. Educ. Pract. Vet. 15:646-655.

Hall, S. J. G., M. A. Vince, E. Shillito-Walser, and P. J. Garson. 1988. Vocalisations of the Chillingham cattle. Behaviour 104:78-104.

Hospes, R., M. Thumes, M. Holsteg, K. Failing, and H. Bostedt. 2005. Estrus induction by means of prostaglandin injection in dairy cows-Comparison of the effectiveness of DL- vs. D-Cloprostenol. Tierarztl. Prax. 33:395.
Ikeda, Y., and Y. Ishii. 2001. Characteristics of cow's voices in time and frequency domains for recognition. Agric. Biosys. Eng. 2:15-23.

Jahns, G., W. Kowalczyk, and K. Walter. 1997. An application of sound processing techniques for determining condition of cows. Pages 105-108 in Proc. 4th Int. Workshop on Systems, Signals and Image Processing. M. Domański and R. Stasiński, ed. Poznan Univ. Technol., Poznan, Poland.

Kiley, M. 1972. The vocalizations of ungulates, their causation and function. Z. Tierpsychol. 31:171-222.

LabVIEW. 1999. Complete software documentation. National Instruments Corporation, Austin, TX.

Laube, R. B., L. Seveke, J. Hubrich, and G. Marx. 1988. Rechnergestützte Lautanalyse beim Kalb zum Nachweis lautontogenetischer Entwicklungsvorgänge. Wiss. Z. KMU Leipzig, Math. Naturwiss. R37:238-244.

Leong, K. M., A. Ortolani, L. H. Graham, and A. Savage. 2003. The use of low-frequency vocalizations in African elephant (Loxodonta africana) reproductive strategies. Horm. Behav. 43:433-443.

Liebenberg, O., S. Polten, and E. Porzig. 1977. Untersuchungen von akustischen Reizen in ihrem stimulierenden Einfluss auf die Lokomotorik von Rindern. 1. Mitt.: Syntax von Kälber- und Bullenlauten. Arch. Tierz. 20:357-365.

Manteuffel, G., B. Puppe, and P. C. Schön. 2004. Vocalization of farm animals as a measure of welfare. Appl. Anim. Behav. Sci. 88:163-182.

Marchant-Forde, J. N., R. M. Marchant-Forde, and D. M. Weary. 2002. Reponses of dairy cows and calves to each other's vocalisation after early separation. Appl. Anim. Behav. Sci. 78:19-28.

Peralta, O. A., R. E. Pearson, and R. L. Nebel. 2005. Comparison of three estrus detection systems during summer in a large commercial dairy herd. Anim. Reprod. Sci. 87:59-72.

Roelofs, J. B., F. J. C. M. van Eerdenburg, N. M. Soede, and B. Kemp. 2005. Pedometer readings for estrous detection and as predictor for time of ovulation in dairy cattle. Theriogenology 64:16901703.

SAS Institute. 2001. SAS/STAT User's Guide. Version 9.1.3. SAS Inst. Inc., Cary, NC.

Saumande, J. 2002. Electronic detection of oestrus in postpartum dairy cows: Efficiency and accuracy of the $\mathrm{DEC}^{\circledR}$ (showheat) system. Livest. Prod. Sci. 77:265-271.

Schneider, F., A. Bellmann, F. Becker, S. Bambang Poernomo, C. Rehfeldt, G. Nürnberg, and W. Kanitz. 2002. Gonadotropin release in periovulatory heifers after $\mathrm{GnRH}$ analogs measured by to types of immunoassays. Exp. Clin. Endocrinol. Diabetes 110:235-244.

Schön, P. C., K. Hämel, and W. Kanitz, inventors. 2005. Verfahren zur Erkennung der Brunst. Forschungsinstitut für die Biologie landwirtschaftlicher Nutztiere, Dummerstorf, Germany, assignee. German Pat. No. 102005032 240.9.

Schön, P. C., B. Puppe, T. Gromyko, and G. Manteuffel. 1999. Common features and individual differences in nurse grunting of domestic pigs (Sus scrofa): A multiparametric analysis. Behaviour 136:49-66.

Semple, S., and K. McComb. 2000. Perception of female reproductive state from vocal cues in a mammal species. Proc. R. Soc. Lond., B, Biol. Sci. 1444:707-712.

Watts, J. M., and J. M. Stookey. 2000. Vocal behaviour in cattle: The animal's commentary on its biological processes and welfare. Appl. Anim. Behav. Sci. 67:15-33. 